\title{
Determination of Doxycycline in Human Plasma by Liquid Chromatography-Mass Spectrometry after Liquid-Liquid Extraction and its Application in Human Pharmacokinetics Studies
}

Muralidharan Selvadurai, Subramania Nainar Meyyanathan*, Sekar Rajan, Govindarajan Padmanaban and Bhojraj Suresh

Department of Pharmaceutical Analysis, J.S.S.College of pharmacy, Ootacamund 643001, Tamilnadu, India

\begin{abstract}
A sensitive and reproducible liquid chromatography-mass spectrometric (LC-MS) method has been developed and validated for the quantification of doxycycline in human plasma, after liquid-liquid extraction (LLE). Best chromatographic resolution was achieved on a reverse-phase Phenomenex $C_{18}$ column using the mobile phase acetonitrile-5mM ammonium acetate (80:20) in isocratic elution with a total run time of $3.5 \mathrm{~min}$. The analyte, doxycycline was detected by using an electrospray ionization mass spectrometer in the selected ion monitoring (SIM) mode. Linear plot was obtained in the concentration range of $0.5-5.0 \mu \mathrm{g} / \mathrm{ml}\left(r^{2}=0.998\right)$. Lower limit of quantification (LLOQ) was found to be $100 \mathrm{ng} / \mathrm{ml}$ in $500 \mu \mathrm{l}$ of plasma. Average recovery of the analyte was found to range from 96.08 to $104.60 \%$ in plasma at the concentrations of $1.0,3.0$ and $5.0 \mu \mathrm{g} / \mathrm{ml}$. Intra- and inter-day relative standard deviation was found to be $0.13-0.74$ and 0.11-0.34 respectively. The present method was successfully applied in the pharmacokinetic study of doxycycline in human plasma.
\end{abstract}

Keywords: Doxycycline; LC-MS; Validation; Pharmacokinetic studies Introduction

Doxycycline a member of tetracycline antibiotic group is commonly used to treat chronic prostatitis and syphilis. Doxycycline shows its poor ultraviolet (UV) absorption characteristics. Hence determination of doxycycline using HPLC-UV will be a hard task, lacks sensitivity and requires long chromatographic run time in biological fluids. Due to the high polarity index of doxycycline, the gas chromatographic (GC) method requires complex and time-consuming derivatization procedures. Limited analytical techniques were available in the assay of doxycycline such as HPLC-DAD as well as liquid chromatography coupled with tandem mass spectrometry (LC/MS/MS). Compared to reported methods (Axisa et al., 2000; Bocker et al., 1983; Cinquina et al., 2003; Croubels et al., 1998; Fiori et al., 2005; Sanderson et al., 2005; Oka et al., 1997; Ruz et al., 2004; Skulason et al., 2003; Santos et al., 1996; Sheridan et al., 1988; Gschwend et al., 2007; Alsarra et al., 2004; Balogh et al., 1991) the present liquid chromatographymass spectrometry method is relatively simple, rapid and highly sensitive in the determination of doxycycline in human plasma after liquid-liquid extraction (LLE) and has been successfully applied in the human pharmacokinetic study.

\section{Experimental}

\section{Chemicals and reagents}

Reference standards of doxycycline (purity: 99.67\%) and oxytetracycline (internal standard, IS 99.01\%) were procured from $\mathrm{M} / \mathrm{s}$. Orchid pharmaceuticals (Chennai, India) and Cadila Pharm (Ahmedabad, India) respectively. HPLC grade acetonitrile was procured from E. Merck (Mumbai, India) and other chemicals used were of analytical grade. Purified water from a Milli-Q-system (Millipore, Bangalore, India) was used throughout the analysis.

\section{Human}

Human studies were approved by human ethical committee, Ooty, India.

\section{Instrumentation}

A Shimadzu 2010 A LC-MS (including two LC-10ADvp pumps) an online vacuum deaerator, a constant temperature automatic sampler, a single quadrupole mass spectrometer equipped with an electrospray ionization interface (ESI) source and LC-MS solution was used for data processing.

\section{Chromatographic conditions}

Liquid chromatographic separations were achieved using a Phenomenex $5 \mu \mathrm{C}_{18}$ column $(100 \mathrm{~mm} \times 4.6 \mathrm{~mm})$. The column and auto sampler tray temperature were kept constant at $40^{\circ}$ and $4{ }^{\circ} \mathrm{C}$, respectively. The mobile phase consisted of a mixture of acetonitrile: $5 \mathrm{mM}$ ammonium acetate $(80: 20)$ and was delivered at a flow-rate of $0.3 \mathrm{ml} / \mathrm{min}$. The sample injection volume was $10 \mu \mathrm{l}$.

\section{Mass spectrometric conditions}

Samples were ionized by positive-ion electrospray ionization mode under the following source conditions: gas flow: $2.5 \mathrm{l} / \mathrm{min}$; curved desolvation line (CDL) voltage was fixed as in tuning, CDL temperature: $250^{\circ} \mathrm{C}$; and block temperature: $200^{\circ} \mathrm{C}$. Mass spectra were obtained at a dwell time of 0.2 and $1 \mathrm{~s}$ for SIM and scan mode accordingly. Analysis was carried out using selected ion monitoring (SIM) for specific $m / z \quad 444.0$ for doxycycline and $m / z \quad 460.0$ for oxy

*Corresponding author: Dr. Subramania Nainar Meyyanathan Ph.D., Professo and Head, Department of pharmaceutical Analysis, J.S.S.College of pharmacy, Ootacamund-643001, Tamilnadu, India, E-mail: meyys@rediffmail.com

Received July 15, 2010; Accepted September 16, 2010; Published September 16,2010

Citation: Selvadurai M, Meyyanathan SN, Rajan S, Padmanaban G, Suresh B (2010) Determination of Doxycycline in Human Plasma by Liquid ChromatographyMass Spectrometry after Liquid-Liquid Extraction and its Application in Human Pharmacokinetics Studies. J Bioequiv Availab 2: 093-097. doi:10.4172/jbb.1000038

Copyright: (c) 2010 Selvadurai M, et al. This is an open-access article distributed under the terms of the Creative Commons Attribution License, which permits unrestricted use, distribution, and reproduction in any medium, provided the original author and source are credited. 
Citation: Selvadurai M, Meyyanathan SN, Rajan S, Padmanaban G, Suresh B (2010) Determination of Doxycycline in Human Plasma by Liquid Chromatography-Mass Spectrometry after Liquid-Liquid Extraction and its Application in Human Pharmacokinetics Studies. J Bioequiv Availab 2: 093-097. doi:10.4172/jbb.1000038

tetracycline. Peak areas for all components were automatically integrated using LC/MS lab solution Version 2.04 (@ 2010 A Shimadzu Corp.).

\section{Preparation of stock solution and sample solutions}

Stock solution of doxycycline was prepared by dissolving the accurately weighed reference compound in water and acetonitrile $(1: 1)$ to give a final concentration of $1 \mathrm{mg} / \mathrm{ml}$, stored at $4^{\circ} \mathrm{C}$ until it is used. The solution was then serially diluted with water and mixed with blank human plasma to achieve standard working solutions at concentration of $0.5,1.0,2.0,3.0,4.0$, and $5.0 \mu \mathrm{g} / \mathrm{ml}$ for doxycycline, respectively. A $2500.0 \mathrm{ng} / \mathrm{ml}$ internal standard working solution was prepared by diluting the $1 \mathrm{mg} / \mathrm{ml}$ stock solution of internal standard with millipore water.

\section{Sample preparation}

A $0.5 \mathrm{ml}$ aliquot of human plasma sample was mixed with $100 \mu \mathrm{l}$ of internal standard working solution $(2500.0 \mathrm{ng} / \mathrm{ml}$ of oxytetracycline) and $1.0 \mathrm{ml}$ of $0.05 \mathrm{M}$ phosphate buffer of $\mathrm{P}^{\mathrm{H}} 7.0$ were added and mixed. The resulting solution was vortexed and extracted with $\mathrm{n}=$ hexane. The upper organic layer was separated, evaporated and the drug was reconstituted using $0.5 \mathrm{ml}$ of the mobile phase and analysed.

\section{Assay Validation (FDA 2001)}

Sensitivity and specificity: The lower limit of quantification was determined as the minimum concentration that could be accurately and precisely quantified (lowest data point of the standard curve). The specificity of the assay for the analytes versus endogenous substances in the matrix was assessed comparing the lowest concentration in the calibration curves with reconstitutions prepared with drug-free plasma from five different humans. Limit of detection was found to be $50 \mathrm{ng} / \mathrm{ml}$ and Limit of quantification is $100 \mathrm{ng} / \mathrm{ml}$.

Accuracy and precision:The accuracy and precision (presented as relative standard deviation, R.S.D.) of the assay were determined using quality control (QC) samples at 1.0, 3.0 and $5.0 \mu \mathrm{g} / \mathrm{ml}$. Accuracy (\%) was determined by the percentage ratio of measured over spiked QC concentration (mean of measured/ spiked $\times 100 \%$ ). Intra-day precision was determined by analyzing replicate aliquots of QCs $(\mathrm{n}=$ 5 per each concentration) on the same day. Inter-day precision was determined by repetitive analysis of QC samples (each concentration) on five consecutive days.

Recovery and ionization:To investigate the recovery of doxycyline by the LLE method, plasma samples were spiked with doxycycline at concentrations of $1.0,3.0$ and $5.0 \mu \mathrm{g} / \mathrm{ml}$. The resulting peak-area ratios (analyte: internal standard) were compared with that of the standards prepared in mobile phase to provide the recovery values. Ion suppression of ionization was evaluated by APCI technique, the absolute peak areas of control plasma extracted and then spiked with a known amount of drug, to neat standards injected directly in the same reconstituted solvent.

Stability: To evaluate sample stability after three freeze-thaw cycles and at room temperature, five replicates of QC samples at each of the low, medium and high concentrations were subjected to three freeze-thaw cycles or were stored at room temperature for $4 \mathrm{~h}$ before sample processing, respectively. Five replicates of QC samples at each of the low and high concentrations were processed and stored under autosampler conditions for $24 \mathrm{~h}$. Stability was assessed by comparing the mean concentration of the stored QC samples with the mean concentration of freshly prepared QC samples.

Clinical design: The study protocol was approved by the Institution ethics committee. Twenty four healthy male Indian subjects with mean age group 20-30 years and average weight $65.8 \pm 6.1 \mathrm{~kg}$ were included in the study. Subjects were excluded from the study if one or more of following criteria were present at time of medical screening: allergic to doxycycline, history or clinical data of renal or liver disease, positive test for hepatitis B, HIV, history of alcohol, drug addiction or donated blood within 72 days prior to study. Test and reference formulations of doxycycline $100 \mathrm{mg}$ tablet were administered with 240 $\mathrm{ml}$ of water. The study was conducted single dose, randomized, open, and complete crossover design. Volunteers were fasted overnight before and $4 \mathrm{~h}$ after drug administration. Blood sample $(5 \mathrm{ml})$ were collected at $0.0,0.5,1.0,1.5,2.0,2.5,3.0,4.0,6.0,8.0,12.0$, 18.0 and $24.0 \mathrm{~h}$ of post drug administration through an indwelling cannula into heparinised glass vials. After drug administration standard breakfast and lunch were provided at 4 and $6 \mathrm{~h}$ post dose. The blood samples were immediately centrifuged, plasma was separated and stored at $-20^{\circ} \mathrm{C}$ until analysed. After a washout period of 7 days, the study was repeated in the same manner to complete the crossover design. The plasma samples obtained at various time intervals were analysed by the HPLC method developed.

Application of the assay: The developed LC-MS assay method was used in the pharmacokinetic study after oral $(100.0 \mathrm{mg})$ administration of doxycycline to human volunteers. Volunteers were fasted for $12 \mathrm{~h}$ before dosing and $4 \mathrm{~h}$ afterwards, with free access to water. The samples were collected in pre-labeled vacutainers containing sodium citrate as the anti coagulant and centrifuged at $4000 \mathrm{rpm}$ for $10 \mathrm{~min}$ at $15^{\circ} \mathrm{C}$ and plasma was collected in pre-labeled sample collection tube. A wash out period of 7 days was observed between the two phases of the study. The samples were stored in the deep freezer at $70 \pm 5^{\circ} \mathrm{C}$ until analyzed by a validated LC-MS method.

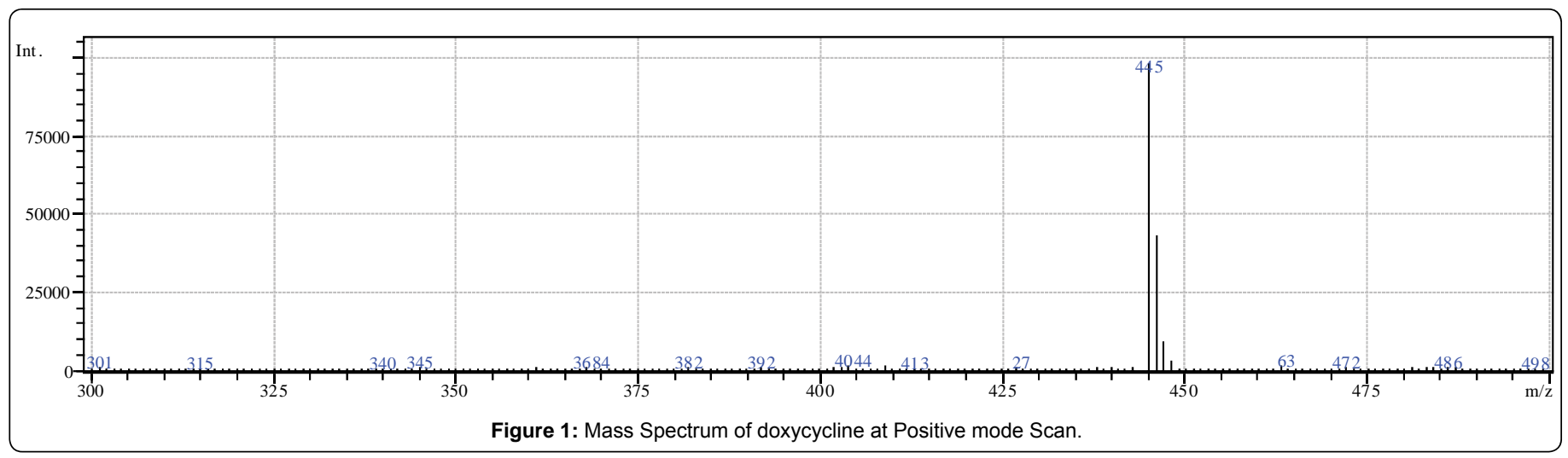




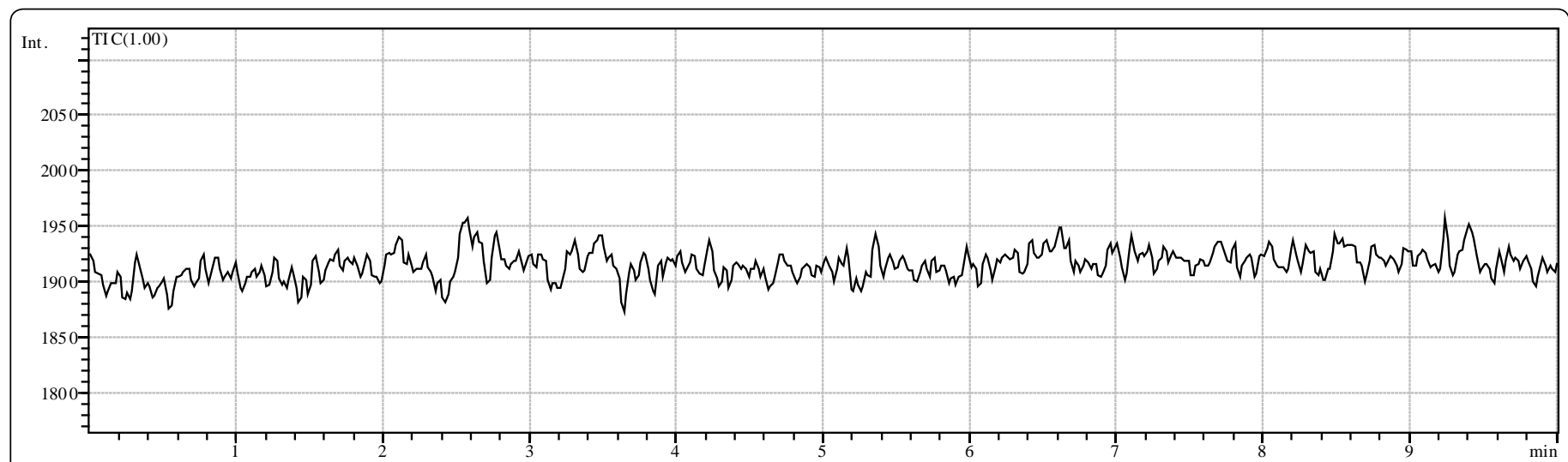

Figure 2: LC-MS chromatogram for the determination of doxycycline in Human Blank plasma.

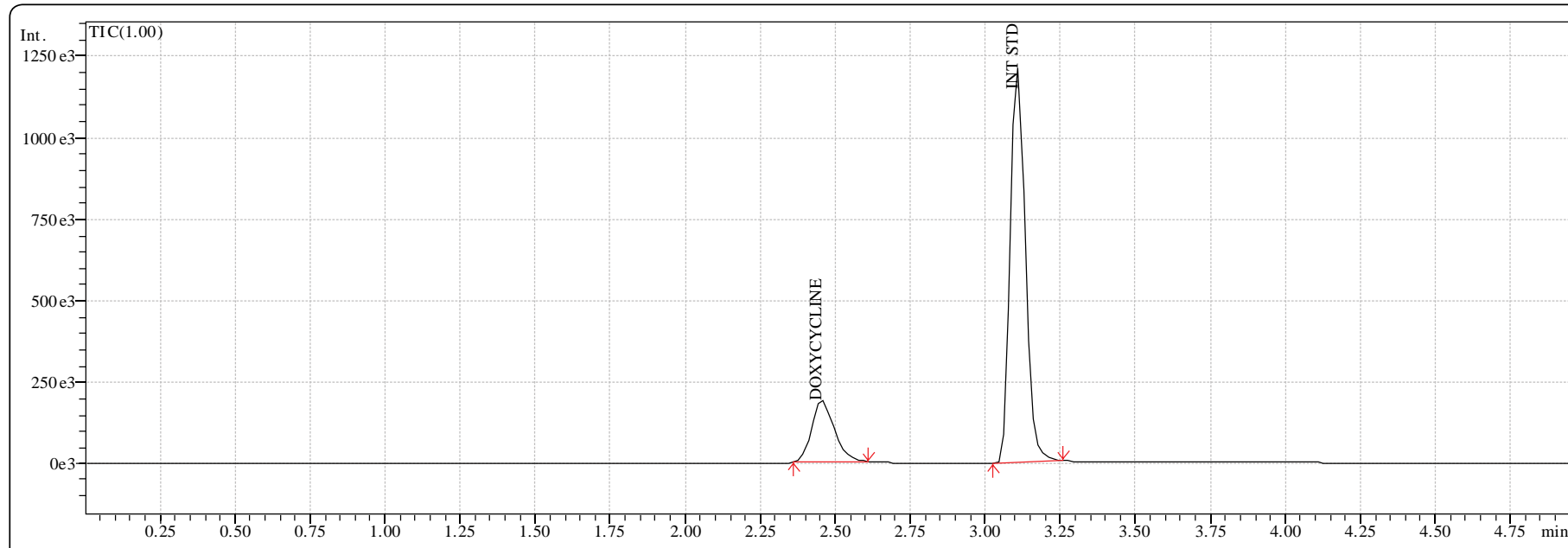

Figure 3: Plasma sample $3 \mathrm{~h}$ after oral administration of doxycycline tablets to human volunteers.

\section{Results and Discussion}

\section{Method development}

Doxycycline is a water soluble drug. Hence, an attempt has been made to extract the drug from plasma by precipitating the plasma samples with solvents like acetonitrile, perchloric acid and methanol. It was found that the analyte recovery was less with these precipitating agents, may be due to decrease in the solubility of doxycycline in water after the addition of these solvents. Therefore liquid-liquid extraction procedure was tried using dichloromethane as extracting solvent. But due to the interference from blank plasma sample when extracted with dichloromethane, a non-polar solvent like n-hexane was tried. Being less polar than dichloromethane it was found that there were no interference from plasma samples when extracted with $\mathrm{n}$-hexane. This proves the satisfactory with $\mathrm{n}$-hexane. The extraction was carried out in one simple step in $0.05 \mathrm{M}$ phosphate buffer $\left(\mathrm{P}^{\mathrm{H}}\right.$ 7.0), which removed interferences due to plasma and yielded cleaner chromatograms. Thus n-hexane was used for sample preparation.

\section{Validation}

Specificity: The full scan mass spectra of doxycycline after direct injection in mobile phase are presented in Figure 1. The predominant protonated molecules found for doxycycline were $\mathrm{m} / z$ 444.00. The mass spectrometric parameters were optimized to obtain the higher signal for the selected ion 460.00 , which also showed less internal interference. While using the isocratic programme, observed retention times were about 2.4 and $3.1 \mathrm{~min}$ for doxycycline and oxytetracycline, respectively. No additional peaks due to endogenous substances that could have interfered with the detection of the compounds of interest were observed. Representative chromatograms for blank plasma (Figure 2), doxycycline and oxytetracycline in volunteers sample are presented in (Figure 3).

Linearity and lower limit of quantification: The linear regression analysis of doxycycline constructed by plotting the peak-area ratio of doxycycline to the internal standard $(y)$ versus analyte concentration $(\mu \mathrm{g} / \mathrm{ml})$ in spiked plasma samples $(x)$. The average regression equation of these curves and their correlation coefficients $(r)$ were calculated as follows: $\mathrm{y}=0.050-0.001\left(r^{2}=0.998, n=7\right)$, weighting coefficient: $1 / x$; it showed good linear relationship between the peak areas and the concentrations. The lower limit of quantitation, defined as the lowest concentration analyzed with accuracy within $\pm 15 \%$ and a precision $\pm 15 \%$, was $5 \mathrm{ng} / \mathrm{ml}$ for determination of doxycycline in plasma. The limit has already been sufficient for pharmacokinetic studies of doxycycline.

Precision: The intra-day precision (presented as relative standard deviation) is shown in Table 1. The precision for concentrations of doxycycline were $6.21,8.71$ and $9.15 \%$, respectively. The accuracy, defined as (measured concentration/spiked concentration) $\times 100 \%$, reached from 95.72 to $98.53 \%$ throughout the four concentrations 
Citation: Selvadurai M, Meyyanathan SN, Rajan S, Padmanaban G, Suresh B (2010) Determination of Doxycycline in Human Plasma by Liquid Chromatography-Mass Spectrometry after Liquid-Liquid Extraction and its Application in Human Pharmacokinetics Studies. J Bioequiv Availab 2: 093-097. doi:10.4172/jbb.1000038

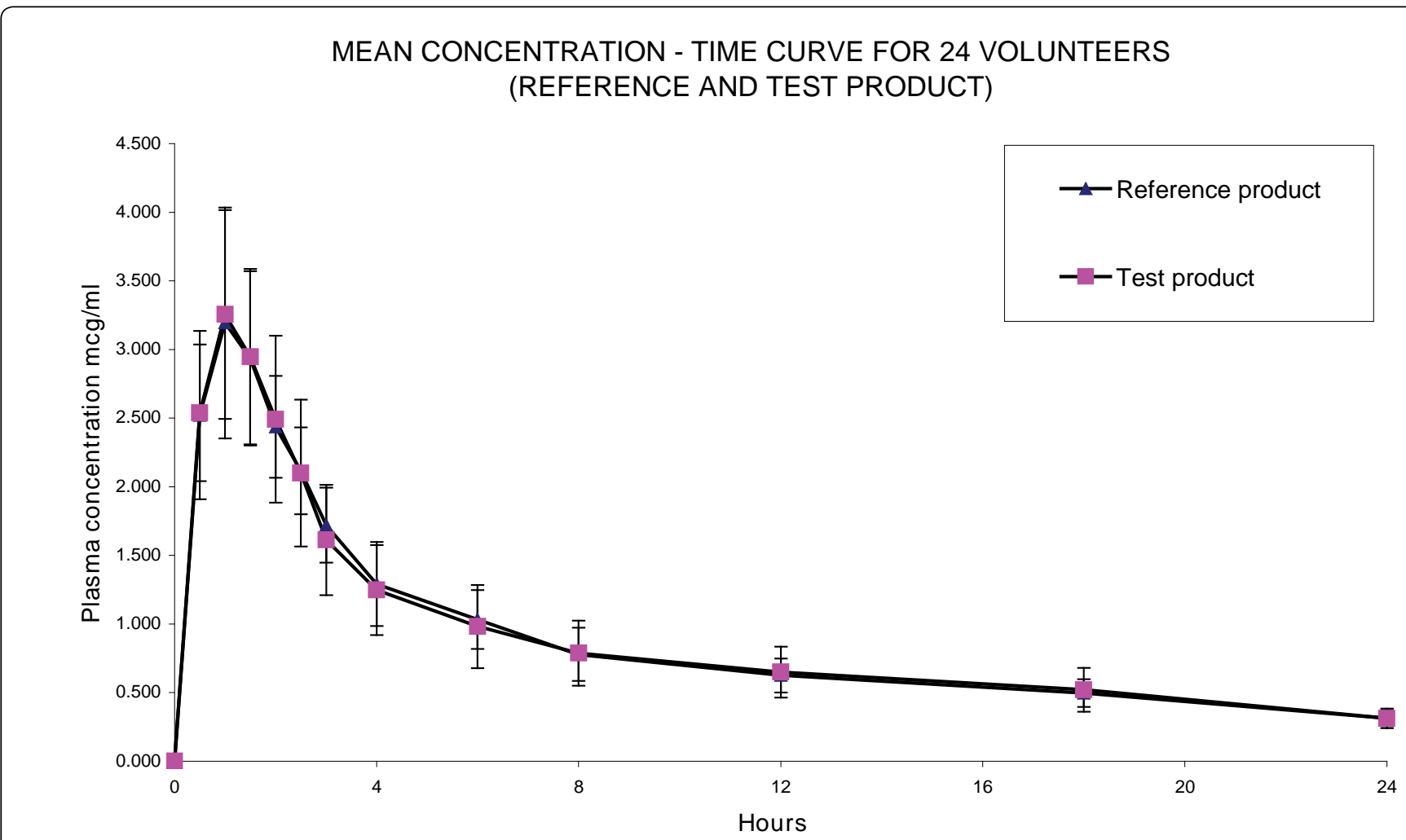

Figure 4: Mean Plasma concentration of Test and Reference product.

\begin{tabular}{|l|l|l|l|}
\hline \multicolumn{4}{|l|}{ Intra day $(\mathrm{n}=5)$} \\
\hline $\begin{array}{l}\text { Nominal concentration } \\
(\mu \mathrm{g} / \mathrm{ml})\end{array}$ & 1 & 3 & 5 \\
\hline Mean \pm S.D & $1.04 \pm 0.13$ & $2.98 \pm 0.18$ & $118.42 \pm 0.74$ \\
\hline Accuracy $(\%)$ & 96.08 & 100.59 & 98.53 \\
\hline R.S.D $(\%)$ & 0.13 & 0.04 & 0.03 \\
\hline \multicolumn{4}{|l|}{} \\
\hline $\begin{array}{l}\text { Nominal Concentration } \\
(\mu \mathrm{g} / \mathrm{ml})\end{array}$ & $1 \mathrm{lnter}$ day $(\mathrm{n}=5)$ & 3 & 5 \\
\hline Mean \pm S.D & 1 & $2.93 \pm 0.11$ & $4.77 \pm 0.34$ \\
\hline Accuracy $(\%)$ & $0.98 \pm 0.11$ & 102.12 & 104.60 \\
\hline R.S.D $(\%)$ & 101.76 & 0.04 & 0.07 \\
\hline & 0.11 & &
\end{tabular}

Table 1: Precision of doxycycline in human plasma.

\begin{tabular}{|l|l|l|}
\hline Pharmacokinetic parameters & Test & Reference \\
\hline AUC $_{0-\mathrm{t}}(\mu \mathrm{g} \cdot \mathrm{h} / \mathrm{ml})$ & 24.67 & 25.50 \\
\hline $\mathrm{AUC}_{0-\infty}(\mu \mathrm{g} \cdot \mathrm{h} / \mathrm{ml})$ & 29.29 & 30.10 \\
\hline $\left.\mathrm{C}_{\max } \mu \mathrm{gg} \cdot / \mathrm{ml}\right)$ & 3.50 & 3.58 \\
\hline $\mathrm{t}_{\max }(\mathrm{h})$ & 1.41 & 1.45 \\
\hline $\mathrm{k}_{\mathrm{eli}}\left(\mathrm{h}^{-1}\right)$ & 0.08 & 0.08 \\
\hline $\mathrm{t}_{1 / 2}(\mathrm{~h})$ & 8.27 & 8.15 \\
\hline
\end{tabular}

Table 2: Pharmacokinetic parameters after oral dose of $100 \mathrm{mg}$ doxycycline oral administration to humans.

examined. The inter-day precision was studied over 5 days, and the results were also given in Table 1.

Recovery and stability: The absolute recoveries of doxycycline at concentrations of $1.0,3.0$ and $5.0 \mu \mathrm{g} / \mathrm{ml}(n=5)$ were $95.60 \pm 5.75$, $96.57 \pm 8.59$ and $98.19 \pm 9.15 \%$, respectively. Stability of doxycycline during sample handling (freeze-thaw and short-term temperature)

and the stability of processed samples were evaluated and doxycycline was stable for at least $4 \mathrm{~h}$ at room temperature in plasma samples, for $24 \mathrm{~h}$ in autosampler conditions and in plasma samples following three freeze-thaw cycles.

Ionization: It was shown that LLE improves the sample clean-up to remove internal substances from plasma and thereby decrease the amount of matrix injected onto the column, thus the ion suppression effect was minimized. The results indicated that there was no significant difference between the signals of analytes extracted from human plasma and the mobile phase, which proves that there were no matrix effects.

Pharmacokinetic study: The assay was conducted to obtain pharmacokinetic data for doxycycline in human plasma after oral administration $(100.0 \mathrm{mg})$ application of the LC/MS method developed here to in vivo pharmacokinetic studies in humans. The area under the plasma concentration (AUCs curve) of doxycycline after oral administrations was 24.67 and $25.50 \mu \mathrm{g} \mathrm{h} / \mathrm{ml}$, respectively. The mean $C_{\max }$ value was 3.50 and $3.58 \mu \mathrm{g} / \mathrm{ml}$ corresponding mean $t_{\max }$ value was 1.41 and $1.45 \mathrm{~h}$. The mean plasma elimination half-life was 8.20 and $8.15 \mathrm{~h}$. for test and reference respectively (Figure. 4), other pharmacokinetic parameters in this study are shown in Table 2. The present method could be applied to pharmacokinetic studies of lower dose administration of doxycycline.

\section{Conclusion}

LLE of doxycycline from plasma was found to be more precise than the solid phase extraction. The current method guarantees a high precision, accuracy, recovery and a relatively short analysis time and will be a useful tool in the pharmacokinetic study of doxycycline in humans. 


\section{References}

1. Alsarra IA, Al-Said MS, Al-Khamis KI, Niazy EM, El-Sayed YM, et al. (2004) Comparative bioavailability study of doxycycline hyclate (equivalent to $100 \mathrm{mg}$ doxycycline) capsules (doxycin vs vibramycin) for bioequivalence evaluation in healthy adult volunteers. Int J Clin Pharmacol Ther 42: 373-377.

2. Axisa B, Naylor AR, Bell PR, Thompson MM (2000) Simple and reliable method of doxycycline determination in human plasma and biological tissues. $J$ Chromatogr B Biomed Sci Appl 744: 359-365.

3. Balogh A, Rechenbach C, Brix R, Mundhenke J, Tjuljumbow R, et al. (1991) The bioequivalence of doxycycline in two preparations in capsule form. Arzneimittelforschung 41: 1289-93.

4. Bocker R (1983) Analysis and quantitation of a metabolite of doxycycline in mice, rats, and humans by high-performance liquid chromatography. J Chromatogr 274: 255-262.

5. Cinquina AL, Longo F, Anastasi G, Giannetti L, Cozzani R (2003) Validation of a high-performance liquid chromatography method for the determination of oxytetracycline, tetracycline, chlortetracycline and doxycycline in bovine milk and muscle. J Chromatogr A 987: 227-233.

6. Croubels S, Vermeersch H, De Backer P, Santos MD, Remon JP, et al. (1998) Liquid chromatographic separation of doxycycline and 4 epidoxycycline in a tissue depletion study of doxycycline in turkeys. J Chromatogr B Biomed Sci Appl 708: 145-152.

7. Fiori J, Grassigli G, Filippi P, Gotti R, Cavrini V (2005) HPLC-DAD and LC-ESIMS analysis of doxycycline and related impurities in doxipan mix, a medicated premix for incorporation in medicated feedstuff. J Pharm Biomed Anal 37: 979985

8. Gschwend MH, Martin W, Erenmemişoğlu A, Scherm M, Dilger C, et al. (2007)
Pharmacokinetics and bioequivalence study of doxycycline capsules in healthy male subjects. Arzneimittelforschung 57: 347-51.

9. Oka H, Ikai Y, Ito Y, Hayakawa J, Harada K, et al. (1997) Improvement of chemical analysis of antibiotics. XXIII. Identification of residual tetracyclines in bovine tissues by electrospray high-performance liquid chromatographytandem mass spectrometry. J Chromatogr B Biomed Sci Appl 693: 337-344.

10. Ruz N, Zabala M, Kramer MG, Campanero MA, Dios-Viéitez MC, et al. (2004) Rapid and simple determination of doxycycline in serum by high-performance liquid chromatography. Application to particulate drug delivery systems. J Chromatogr A 1031: 295-301.

11. Sanderson $H$, Ingerslev F, Brain RA, Halling-Sørensen B, Bestari JK, et al. (2005) Dissipation of oxytetracycline, chlortetracycline, tetracycline and doxycycline using HPLC-UV and LC/MS/MS under aquatic semi-field microcosm conditions. Chemosphere 60: 619-629.

12. Santos MD, Vermeersch $H$, Remon JP, Schelkens M, De Backer P, et al (1996) Validation of a high-performance liquid chromatographic method for the determination of doxycycline in turkey plasma. J Chromatogr B Biomed Appl 682: 301-308.

13. Sheridan ME, Clarke GS (1988) Improved high-performance liquid chromatographic determination of doxycycline in serum and urine using solidphase extraction columns. J Chromatogr 434: 253-258.

14. Skúlason S, Ingólfsson E, Kristmundsdóttir T (2003) Development of a simple HPLC method for separation of doxycycline and its degradation products. $J$ Pharm Biomed Anal 33: 667- 672.

15. US Department of Health and Human Services, Food and Drug Administration, Centre for Drug Evaluation and Research (CDER), Center for Veterinary Medicine (CVM) (2001) FDA Guidance for Industry, Bioanalytical Method Validation. 